\title{
Medipal SPIBntP Contact lenses usage across the western regions of Saudi Arabia
}

\author{
Ahmed A Basheikh ${ }^{1}$, Reham AlJehani ${ }^{1}$, Ola H \\ Abudaowd $^{2}$, Nada A Bugshan ${ }^{2}$
}

To Cite:

Basheikh AA, AlJehani R, Abudaowd OH, Bugshan NA. Contact lenses usage across the western regions of Saudi Arabia. Medical Science, 2022, 26, ms53e1886.

doi: https://doi.org/10.54905/disssi/v26i120/ms53e1886

Author Affiliation:

'Department of ophthalmology, King Abdulaziz University, Jeddah, Saudi Arabia

${ }^{2}$ Faculty of medicine, King Abdulaziz University, Jeddah, Saudi Arabia

Contact Information

Ahmed A Basheikh basheikh_ahmed@yahoo.com

Reham AlJehani rehamaljehanii@gmail.com

Ola H Abudaowd Ola.Abudaowd@gmail.com

Nada A Bugshan nada.bugshan73@gmail.com

Peer-Review History

Received: 07 November 2021

Reviewed \& Revised: 08 November/2021 to 26/January/2022

Accepted: 28 January 2022

Published: 30 January 2022

Peer-review Method

External peer-review was done through double-blind method.

URL: https://www.discoveryjournals.org/medicalscience

\section{(c) (i)}

This work is licensed under a Creative Commons Attribution 4.0 International License.

\begin{abstract}
Introduction: The use of contact lenses for various purposes is steadily gaining popularity over the years. It is crucial that the awareness surrounding its use and care should be properly communicated to avoid undesirable outcomes associated with its use. Methodology: This cross-sectional study deployed a validated, self-administered electronic questionnaire among 1930 participants in the western regions of the Kingdom of Saudi Arabia. Demographic characteristics, as well as questions about their practice in wearing and taking care of their contact lenses, were asked and were used to gauge their usage behavior score. Results: The prevalence of contact lenses usage is relatively high (58.9\%) with women comprising $94.4 \%$ of the users. $7.30 \%$ of the users exhibited an "excellent" score, $62.70 \%$ demonstrated a "good" score, while the remaining 30\% achieved a "poor" score. Conclusion: Although the Saudi population in the area under study is generally aware about the proper usage and care of contact lenses, improvements in practices such as care visits to ophthalmologists/optometrists, changing the container, and changing the contact lens solution, are needed.
\end{abstract}

Keywords: Contact lenses, prevalence, awareness, complications, hygienic practice.

\section{INTRODUCTION}

Contact lenses (CLs) have been widely worn for more than a hundred years now for various reasons such as correction of refractive errors, as well as a therapeutic modality to protect the cornea and heighten its healing process (Lee et al., 2012). Since the introduction of contact lenses for the purposes of cosmetics in 1980, CLs has been steadily gaining popularity throughout the years (U.S. Food and Drug Administration, 2016). The use of CLs has dramatically expanded, and an increase in usage is anticipated due to the escalation of cases involving refractive errors worldwide (Tajunisah et al., 2008). If used properly and in accordance with the guidelines (Boyd, 2021), CLs provide a safe and effective approach for vision correction (Cope et al., 2016). Nevertheless, improper use of CLs, particularly with regards to cleaning and storage, are associated with a wide variety of complications (Suvajac, 2008; Dakhil et al., 2020; Albasheer et al., 2021). A prospective study covering the years 1995-2004 revealed that 494 out of 510 patients wearing soft contact lenses faced various significant complications, ranging from 
conjunctivitis to corneal vascularization and deposition (Suvajac, 2008). A collection of surveys in the United States in 2018 with contact lens wearers and eye care providers as subjects concluded that one-third of lens wearers recalled not hearing any form of lens care recommendation (2019). This apparent lack of proper communication demonstrates their vulnerability to the possible complications associated with improper use and care for contact lenses.

In Saudi Arabia, the usage of CLs is common; a study done in Riyadh in 2014 found that the CL use prevalence was $70.2 \%$ (1029 out of 1466) among female university students, primarily for cosmetic purposes (63.3\%) (Abahussin et al., 2014). While the general awareness surrounding the proper use and care of CLs is relatively high, some respondents admit sharing their CLs with friends (Abahussin et al., 2014). Additionally, a number of shops admit selling CLs even without prescription (Abahussin et al., 2014). Another study on university students of Umm Al-Qura University in Saudi Arabia revealed that more than 50\% of their respondents experienced eye complications related to the improper care of CLs (Bamahfouz et al., 2016).

There is a need for more studies to provide information on CLs' usage, their related behavioral risk factors, hygiene knowledge, and awareness of the possible complications among the Saudi population. As the previously mentioned Saudi studies surveyed university students which are characterized with a relatively higher level of education, results cannot be generalized and may not be reflective of the whole Saudi population. This study was conducted to determine the prevalence and general awareness surrounding CL usage and care across the western regions of Saudi Arabia.

\section{MATERIALS AND METHODS}

This study utilized a cross-sectional approach, Included participants were $>18$ years old, from the general population of western region of Saudi Arabia, specifically from Jeddah, Mecca and Altaif cities. Participants filled out a validated, self-administered electronic questionnaire conducted during September 2020- January 2021. While the validity of the respondents was assessed, participant details were anonymized.

The questionnaire is composed of two sections: the first one deal with the sociodemographic variables while the second one consists of 14 questions used to gauge the general awareness and care regarding the contact lenses usage. Follow-up histories with an ophthalmologist, as well as the medical history regarding complications were also noted. Responses exhibiting the correct/proper behavior will be assigned a numerical value of 1 , while incorrect/improper behavior is equivalent to 0 . A criterion (CL usage behavior score) was then set to evaluate the degree of awareness based on the cumulative points: 1-6 corresponds to "poor"; 7-10 pertains to "good"; and 11-14 demonstrates "excellent" understanding of the guidelines regarding to the usage and care of contact lenses.

Statistical analysis was performed using IBM SPSS version 23 (IBM Corp., Armonk, N.Y., USA) and visually presented by using GraphPad Prism version 8 (GraphPad Software, Inc., San Diego, CA, USA). Simple descriptive statistics was used to define the characteristics of our study variables through standard deviations and means for the continuous variables, while percentages and counts are used for the categorical and nominal variables. To establish a relationship between the categorical variables, the chisquare test was used. One-way ANOVA was utilized in comparing the means of three or more independent groups, with least significant different (LSD) as the post hoc test. All tests were done with the assumption of a normal distribution. Lastly, a conventional $p$-value $<0.05$ was used to reject the null hypothesis. This study is in accordance with the ethical standards set by the Unit of Biomedical Ethics of King Abdulaziz University, with a reference number 743-19. Consent was obtained from all of the participants.

\section{RESULTS}

To assess the prevalence of contact lenses usage among the western Saudi Arabian population, this study administered an electronic questionnaire to 1930 individuals. The demographic characteristics of the study population are summarized in Table 1.

Table 1 Demographic characteristics of the respondents who use contact lenses and its relationship with their CL usage behavior scores

\begin{tabular}{|l|l|l|l|l|l|l|}
\hline \multirow{2}{*}{ Demographic variables } & \multirow{2}{*}{ Count } & \multicolumn{2}{l|}{ CL usage behavior score } & \multirow{2}{*}{$p$-value } \\
\cline { 3 - 6 } & & & Poor & Good & Excellent & \\
\hline \multirow{2}{*}{ Total } & 1136 & $341(30.0 \%)$ & $712(62.7 \%)$ & $83(7.3 \%)$ & - \\
\hline \multirow{2}{*}{ Age } & $18-20$ years old & 174 & $55(31.6 \%)$ & $107(61.5 \%)$ & $12(6.9 \%)$ & \multirow{2}{*}{$<0.001^{\text {a }}$} \\
\cline { 3 - 6 } & $21-30$ years old & 567 & $201(35.4 \%)$ & $342(60.3 \%)$ & $24(4.2 \%)$ & \\
\hline
\end{tabular}




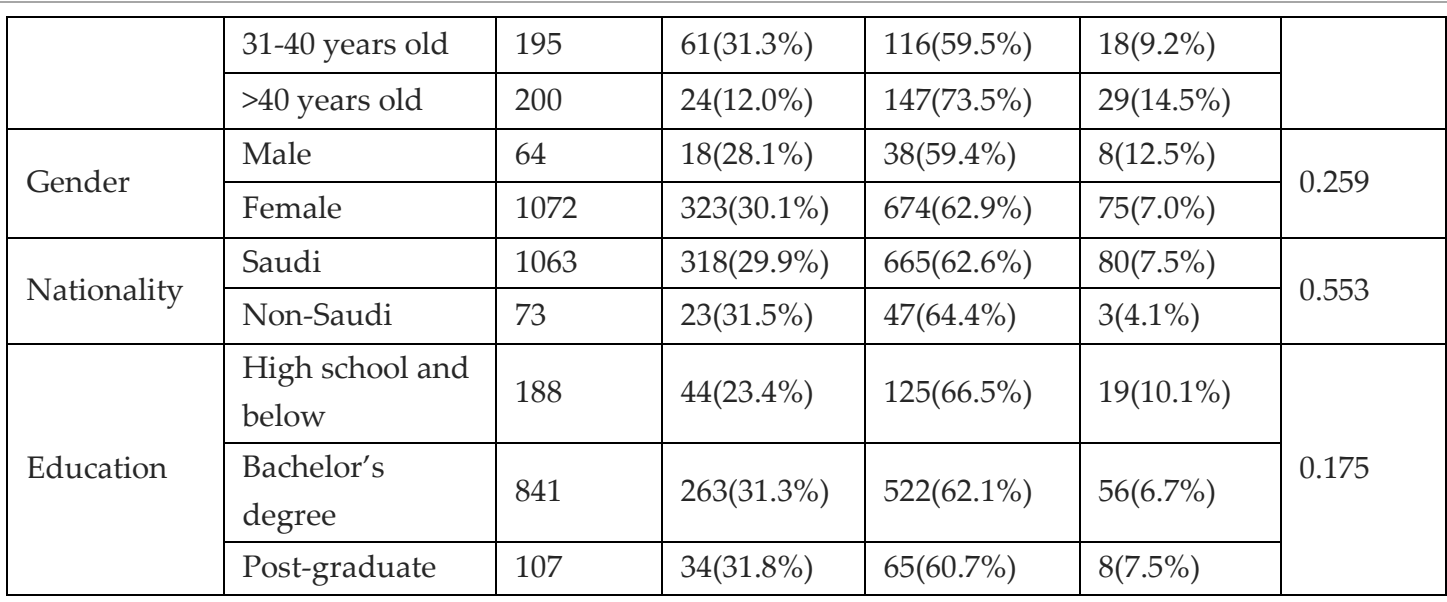

asignificant at $p<0.05$ using chi-square test

Half of the population under study belong to the 21-30 years old age bracket. The sample is also predominantly female (94.4\%). Saudi nationals comprise $93.6 \%$ of the study population and almost three-fourths have at least a bachelor's degree. The chi-square test revealed a significant difference in terms of CL usage behavior scores across the different age groups ( $p<0.001$ ). Out of 1930 individuals, $1136(58.9 \%)$ are CL users. Majority (83.7\%) of these CL users confirmed being taught proper care for contact lenses (Table 2).

Table 2 Nature of CLs use among respondents and its relationship with their CL usage behavior score.

\begin{tabular}{|c|c|c|c|c|c|c|}
\hline \multirow{2}{*}{\multicolumn{2}{|c|}{ Question }} & \multirow{2}{*}{ Total } & \multicolumn{3}{|c|}{ CL Usage Behavior Score } & \multirow{2}{*}{ p-value } \\
\hline & & & Poor & Good & Excellent & \\
\hline \multicolumn{2}{|l|}{ Total } & 1136 & $341(30.0 \%)$ & $712(62.7 \%)$ & $83(7.3 \%)$ & - \\
\hline \multicolumn{2}{|c|}{ At what age did you start wearing CLs? } & 1136 & $17.67 \pm 3.9$ & $22.74 \pm 74.5$ & $24.54 \pm 9.8$ & 0.377 \\
\hline \multirow{4}{*}{$\begin{array}{l}\text { How long have you been } \\
\text { using CL? }\end{array}$} & Less than a year & 225 & $50(22.2 \%)$ & $150(66.7 \%)$ & $25(11.1 \%)$ & \multirow{4}{*}{$0.007^{a}$} \\
\hline & $1-4$ years & 288 & $88(30.6 \%)$ & $181(62.8 \%)$ & $19(6.6 \%)$ & \\
\hline & $5-10$ years & 311 & $112(36.0 \%)$ & $185(59.5 \%)$ & $14(4.5 \%)$ & \\
\hline & More than 10 years & 312 & $91(29.2 \%)$ & $196(62.8 \%)$ & $25(8.0 \%)$ & \\
\hline \multirow{2}{*}{$\begin{array}{l}\text { Were you taught how to } \\
\text { care for CLs? }\end{array}$} & No & 185 & $93(50.3 \%)$ & $92(49.7 \%)$ & $0(0.0 \%)$ & \multirow{2}{*}{$<0.001^{\text {a }}$} \\
\hline & Yes & 951 & $248(26.1 \%)$ & $620(65.2 \%)$ & $83(8.7 \%)$ & \\
\hline \multirow{3}{*}{ Why do you wear CLs? } & Medical & 295 & $88(29.8 \%)$ & $175(59.3 \%)$ & $32(10.8 \%)$ & \multirow{3}{*}{$0.001^{\mathrm{a}}$} \\
\hline & Cosmetic & 497 & $139(28.0 \%)$ & $338(68.0 \%)$ & $20(4.0 \%)$ & \\
\hline & Both & 344 & $114(33.1 \%)$ & $199(57.8 \%)$ & $31(9.0 \%)$ & \\
\hline \multirow{5}{*}{$\begin{array}{l}\text { How frequent do you } \\
\text { use CL on average? }\end{array}$} & Daily & 162 & $74(45.7 \%)$ & $71(43.8 \%)$ & $17(10.5 \%)$ & \multirow{5}{*}{$<0.001^{\mathrm{a}}$} \\
\hline & 1-3 days a week & 115 & $44(38.3 \%)$ & $60(52.2 \%)$ & $11(9.6 \%)$ & \\
\hline & 4-6 days a week & 116 & $50(43.1 \%)$ & $57(49.1 \%)$ & $9(7.8 \%)$ & \\
\hline & 1-2 days a month & 195 & $56(28.7 \%)$ & $128(65.6 \%)$ & $11(5.6 \%)$ & \\
\hline & Only few days/year & 548 & $117(21.4 \%)$ & $396(72.3 \%)$ & $35(6.4 \%)$ & \\
\hline \multirow{4}{*}{$\begin{array}{l}\text { How long do you wear } \\
\text { CLs? }\end{array}$} & Less than 6 hours & 417 & $72(17.3 \%)$ & $312(74.8 \%)$ & $33(7.9 \%)$ & \multirow{4}{*}{$<0.001^{\mathrm{a}}$} \\
\hline & 6-11 hours & 586 & $185(31.6 \%)$ & $353(60.2 \%)$ & $48(8.2 \%)$ & \\
\hline & 12- 24 hours & 109 & $67(61.5 \%)$ & $40(36.7 \%)$ & $2(1.8 \%)$ & \\
\hline & More than 24 hours & 24 & $17(70.8 \%)$ & $7(29.2 \%)$ & $0(0.0 \%)$ & \\
\hline \multirow{2}{*}{$\begin{array}{l}\text { Complications } \\
\text { experienced as a result of } \\
\text { wearing CL }\end{array}$} & $\begin{array}{l}\text { Didn't have any } \\
\text { complication }\end{array}$ & 431 & $98(22.7 \%)$ & $292(67.7 \%)$ & $41(9.5 \%)$ & \multirow[t]{2}{*}{$<0.001^{a}$} \\
\hline & Had complications & 705 & $243(34.5 \%)$ & $420(59.6 \%)$ & $42(6.0 \%)$ & \\
\hline
\end{tabular}

asignificant at $p<0.05$ using chi-square test

A third (32.3\%) of the individuals who were taught proper care of contact lenses learned from a family member, $29.9 \%$ learned from online resources and social media, and around $21.5 \%$ were taught by an ophthalmologist or an optometrist. Reasons for using 
CLs among the study population is primarily for cosmetic purposes (43.8\%), while $26.0 \%$ are for medical purposes; the remaining proportion of individuals use CLs for both cosmetic and medical reasons. About half of the study population use CLs only a few days per year and about the same proportion uses it for 6-11 hours at a time. In terms of the type of CLs used, $45 \%$ of the respondents wear monthly disposable CLs, $42.1 \%$ uses extended wear soft CLs, and $28.1 \%$ uses daily disposable soft CLs. Responses to other pertinent questions and the results of statistical analysis are summarized in Table 3.

Responses to the 14 questions regarding the actual behavior of CL users in the context of use and care of CLs are listed in Table 3. Notice how majority of CL users under study observe the proper behavior in different aspects except for washing and changing the container, changing the solution, obtaining prescription, and conducting consultations with ophthalmologists and optometrists.

Table 3 Summary of responses to the 14 questions regarding use and care of CLs

\begin{tabular}{|l|l|l|}
\hline Question & $\begin{array}{l}\text { Correct } \\
\text { behavior }\end{array}$ & \multicolumn{2}{l|}{ Incorrect behavior } \\
\hline Total & 1136 & $220(19.4 \%)$ \\
\hline Do you sleep with CL on? & $916(80.6 \%)$ & $293(25.8 \%)$ \\
\hline Do you shower with CL on? & $843(74.2 \%)$ & $223(19.6 \%)$ \\
\hline Do you swim with CL on? & $913(80.4 \%)$ & $191(16.8 \%)$ \\
\hline Do you share your CL with others? & $945(83.2 \%)$ & $307(27 \%)$ \\
\hline Do you wash your hand pre and post wearing the CL? & $829(73.0 \%)$ & $272(23.9 \%)$ \\
\hline $\begin{array}{l}\text { Do you wash or store the CL in other solutions? (e.g. } \\
\text { water) }\end{array}$ & $864(76.1 \%)$ & $775(68.2 \%)$ \\
\hline Do you wash the CL container? & $361(31.8 \%)$ & $506(44.5 \%)$ \\
\hline Do you wear the CL after it's expiry date? & $630(55.5 \%)$ & $473(41.6 \%)$ \\
\hline $\begin{array}{l}\text { Do you wear CL longer than their designed duration of } \\
\text { use? }\end{array}$ & $663(58.4 \%)$ & $1002(88.2 \%)$ \\
\hline How frequent do you change the CL solution? & $134(11.8 \%)$ & $976(85.9 \%)$ \\
\hline Do you change the CL container? & $160(14.1 \%)$ & $294(25.9 \%)$ \\
\hline Do you abstain from wearing CL during sandstorms? & $842(74.1 \%)$ & $673(59.2 \%)$ \\
\hline $\begin{array}{l}\text { Did an Ophthalmologist/optometrist/optician prescribe } \\
\text { the CL? }\end{array}$ & $463(40.8 \%)$ & $7066(93.8 \%)$ \\
\hline $\begin{array}{l}\text { Do you visit ophthalmologists/optometrists/opticians } \\
\text { for eye or CLs follow-up? }\end{array}$ & $70(6.2 \%)$ & \\
\hline
\end{tabular}

The CL usage behavior score of the study population is visualized in Figure 1. Majority (62.70\%) of the respondents exhibit a "good" CL usage behavior score, about a third (30\%) obtained a "poor" score, and 7.30\% were able to achieve an "excellent" rating. To establish reliability and consistency of the ratings for the behavior score based on the 14 questions, the statistical variable Cronbach's alpha was used. Using $\mathrm{N}$ of items as 14, the value for the Cronbach's alpha was calculated to be 0.534.

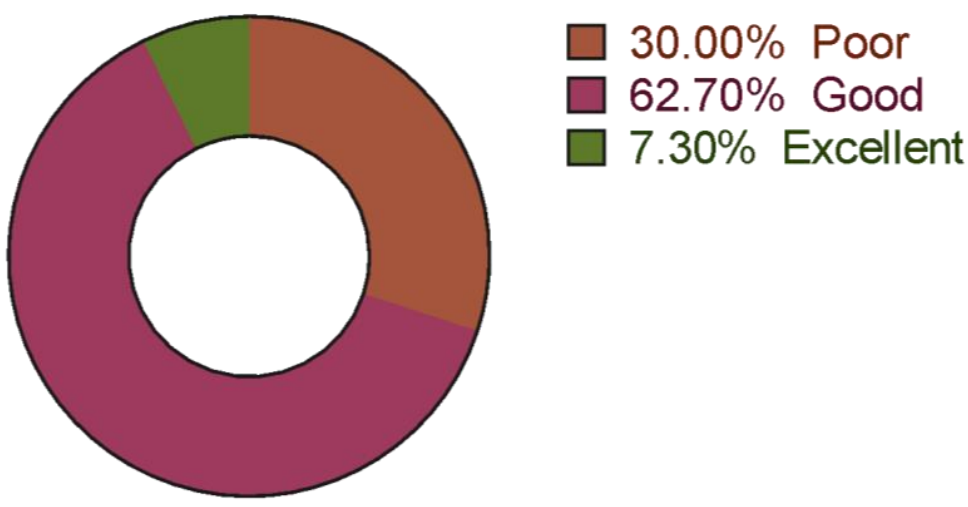

Figure 1 CL Usage Behavior Score 


\section{DISCUSSION}

Wearing contact lenses is becoming more and more popular; partly due to the increase in diagnosis of refractive errors worldwide and partly due to the demand in the cosmetic aspect (Tajunisah et al., 2008). In universities in Saudi Arabia, as much as 70\% of female university students wear contact lenses and are generally aware with its use and care (Abahussin et al., 2014). However, conclusions of this study cannot be generalized to the general Saudi population. This study aims to bridge that gap, and obtain an overview of the prevalence and awareness surrounding the usage and care of contact lenses in the Saudi population residing in the western regions.

Out of 1930 respondents, 1136 (58.9\%) were users of contact lenses. The prevalence of CL users in the sample population is relatively high compared to other studies; Ibrahim et al., (2018) noted a 40.5\% prevalence among medical students of King Abdulaziz University (KAU). A study in 8 universities in China revealed a 19.8\% prevalence of CL use (Zhu et al., 2018). The differences in occurrence of CL use among the study populations can be attributed to the study design, the inclusion/exclusion criteria, and survey methods. Among the CL users, women far outnumbered men, comprising as much as $94.4 \%$. This is consistent with the observations of other studies; Ibrahim et al., (2018) analyzed the prevalence of CL use in KAU, with CL users dominated by women $(88 \%)$.

The study in Chengdu, China also noted that most users (82.15) of CLs in their study were women (Zhu et al., 2018). This observation may be due to the fact that as much as 74\% of CL users do so for cosmetic purposes (Ibrahim et al., 2018). Moreover, the high proportions of CL users for the purpose of cosmetics have also been noted in other studies (Bamahfouz et al., 2016; Ibrahim et al., 2018; Unnikrishnan et al., 2009). Most of the CL users choose to wear monthly disposable soft CL which concurs with the studies of Unnikrishnan et al., (2009) and Stapleton et al., (2007). In Italy, daily CL was the modality of choice because of its relatively inexpensive cost (Abbouda et al., 2016). Soft contact lenses are commonly used because of their ease of use, and they do not require high maintenance. However, while soft lenses can lessen the risk of eye infection, they are often ineffective in vision correction (American Optmometric Association).

As summarized in Table 3 and shown in Figure 2, majority of the respondents practice proper hygiene in using and handling contact lenses. According to the American Optometric Association, CLs care systems are very important in reducing the risk of infections. In this study, a huge proportion of the respondents observe the proper practice of removing their CLs before engaging in water activities (i.e. swimming, bathing) or sleeping. Stapleton et al., (2007) mentioned that swimming and bathing while wearing CLs increase the risk of Acanthamoeba keratitis, along with improper disinfection of soft lenses. They recommended the use of daily disposable lenses, if removing CLs during water activities is not an option. When it comes to sleeping, it is regarded to be one of the highly reported risk behavior associated with the use of CLs (Cope et al., 2016). The risk of corneal infection is increased, and the eyes become susceptible to diseases such as fungal, bacterial, or Acanthamoeba keratitis; not to mention the risk is even higher when CLs have been contaminated during the day (Goodlaw, 1996). Most users (83.2\%) denied sharing their CL with others. Abahussin et al., (2014) noted occasional sharing of CLs in $27.6 \%$ of their study population. The risks posed by this behavior include crosscontamination and cross-infection.

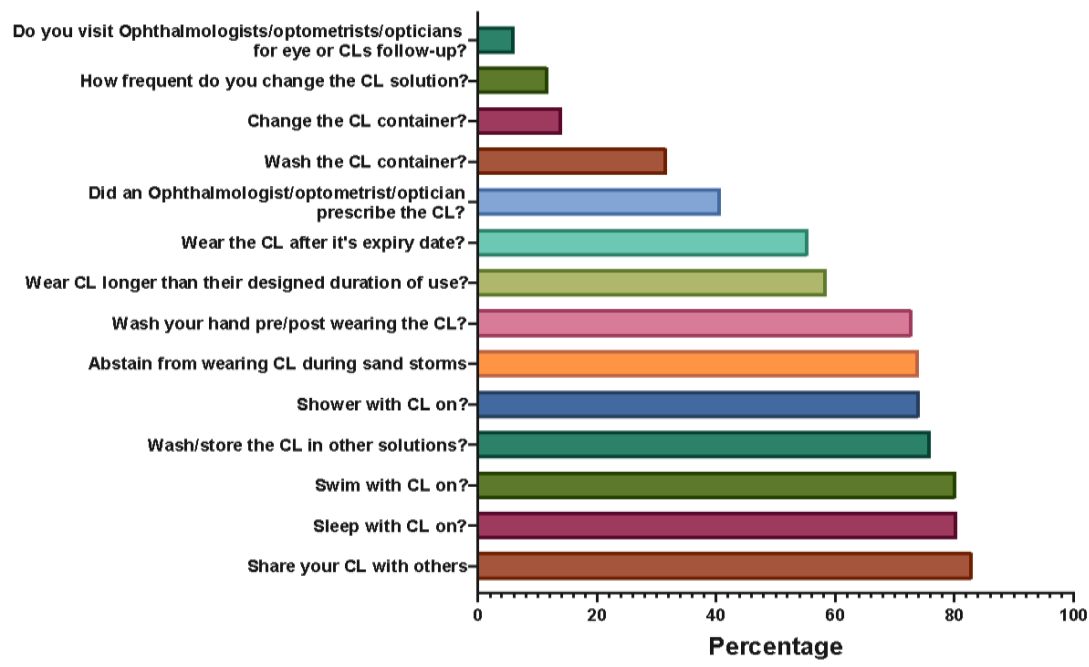

Figure 2 Percentage of CL users and their Hygienic Practices. 
The present study has shown that $73.0 \%$ of the population under study wash their hands pre and post wearing contact lenses. This is a higher percentage compared to the results of a study from Maldives, with $44.2 \%$ of their sample population washing their hands (Gyawali et al., 2014). However, similar studies conducted in the universities in Chengdu showed a higher proportion $(86.20 \%)$; while a university in Riyadh revealed that $89.4 \%$ of their sample population practice washing their hands (Abahussin et al., 2014; Zhu et al., 2018). Poor hand washing can lead to acute eye inflammation and infections such as microbial keratitis (Lievens et al., 2017). The probability of these health risks occurring is particularly inflated in cases where cosmetic CLs were not prescribed by ophthalmologists and optometrists (Cope et al., 2016).

Majority $(76.1 \%)$ of the participants did not store or rinse their CLs in any other types of solutions (e.g. tap water, drinking water). Keeping CLs in non-standard solutions raises the risk of infection, as these solutions may harbor in them pathogenic microorganisms which can colonize the CLs, cause an eye infection, and irritate the eyes (Stapleton et al., 2007). Washing the container of CLs, the frequency of changing the CL solution, and changing the CL container are among the weakest links in the use and care behavior of the respondents. Abahussin et al., (2014) noted that $72.7 \%$ of female university students changed their CL solutions daily, contrary to the $11.8 \%$ from this study. $68.5 \%$ of the sample population under study regularly wash their CL containers, while $54.4 \%$ admitted not changing their CL containers ever. This figure is relatively lower compared to the results of Berenson et al., (2019), where as much as 76.5\% of American adolescents responded that they have not changed their CL containers even at least once. Contamination occurs in lens containers due to the moistened surfaces of the CL and the containers which provide a setting convenient for microbial growth (Becmeur et al., 2017; Kilvington et al., 2011). Studies have shown that CL cases that were replaced every nine months had lower risk of contamination than cases that were not replaced (Abahussin et al., 2014; $\mathrm{Wu}$ et al., 2010).

Three out of four contact lens users in the sample population abstain from wearing contact lenses during sandstorms which are a common phenomenon in Saudi Arabia. During this event, dust particles can become lodged under the lens, irritate the eye and may lead to corneal ulcer development; not to mention, these dust particles can also harbor pathogenic microorganisms that can cause microbial infection of the eye (Vijayakumar et al., 2017). Majority (59.2\%) of CL users under study obtained their CLs without a prescription from an ophthalmologist/optometrist. In the same note, 71.3\% of CL users never paid an ophthalmologist/optometrist a visit for follow-up or consultation. This is particularly concerning, as this practice may be the leading cause for development of complications if proper use and care was not communicated effectively to the CL users. This ongoing problem has been observed in the study of Abahussin et al., (2014) where they mentioned that as much as 815 out of the 1327 shops they surveyed admitted to not giving instructions to the consumer about use and care during the purchase of CLs.

Additionally, lack of care visits have been also reported in other studies; $62.9 \%$ of college students from Umm Al-Qura University never did a consultation with an ophthalmologist/optometrist (Bamahfouz et al., 2016). A South African study on adolescents also noted the problem in compliance with care visits among their study population (Khoza et al., 2020). With mishandling, improper hygiene observance and insufficient knowledge about the usage of CL, complications may arise. In this study, more than half of the users (62.1\%) experienced some form of complication. Pain and discomfort in the eyes affected $48.2 \%$ of CL users, itchy watery eyes affected $30.3 \%$ of CL users, and red swollen eyes have been noted in $17.3 \%$ of the sample under study.

According to $\mathrm{AAO}$, these complications are common among CL users. It is also noticeable in the results that only a few experienced serious cases such as corneal ulcer $(1.8 \%)$ and blindness $(0.4 \%)$. Corneal ulcer is usually caused by bacterial, fungal or parasitic/acanthamoeba infections (Nichols et al., 2013). Serious cases of corneal ulcer could eventually lead to blindness. CL usage behavior scores of the users were evaluated and summarized in Figure 1. The study showed that users generally exhibited "good" understanding of the usage and care of CLs. The calculated value of Cronbach's alpha is 0.534 which is generally considered a manifestation of poor consistency and reliability. However, it should be pointed out that there are no technical standards for Cronbach's alpha, as it is still dependent on the methods' nature. Additionally, some publications suggest that a Cronbach's alpha greater than 0.50 denotes moderate reliability (Hinton et al., 2014).

Statistical analyses revealed a significant difference in CL usage behavior scores among the different age groups, as shown in Table 1. This resonates with the results of surveys in cities in the United States, where they noted age being a significant predictor of behavior and compliance to guidelines regarding CL use and care (Bui et al., 2010; Wagner et al., 2014). Specifically, Wagner et al., (2014) observed that young adults exhibited poorer compliance compared to other age groups. In this study, the best CL usage behavior scores seem to be coming from CL users greater than 40 years old. Other pertinent variables such as years of usage, reason for using CLs, frequency and duration of CL usage, and experiences with complications showed significant relationship with behavior score of CL users. This means that these variables or questions are significant predictors of the CL usage behavior scores. Overall, the results of the statistical analysis imply that people who are experienced and are well-informed about CL use and care 
exhibit better CL usage behavior scores; this has also been documented in a different study which used a different scale/criterion (Alobaidan et al., 2018).

Limitations of this study include the inherent biases of the methodology implemented, such as response and recall bias. This study also cannot establish concrete causal relationships between the variables under study, given the nature of a cross-sectional study.

\section{CONCLUSION}

Although the population in western Saudi Arabia is generally knowledgeable and practices the proper use and care of contact lenses, there is still a gap when it comes to care visits and consultation with ophthalmologists/optometrists. Additionally, there needs to be an improvement in terms of the frequency of changing the CL solution and the CL container. It is recommended that the necessity of these actions be communicated effectively towards the consumers during purchase of CLs.

\section{Acknowledgements}

We thank the participants who were all contributed to the study by filling the questionnaire.

\section{Ethical approval}

The study was approved by the Medical Ethics Committee of King Abdulaziz University, Jeddah, Saudi Arabia (ethical approval code: 743-19).

\section{Authors' contributions}

Ahmed A.Basheikh: research Idea, literature review, questionnaire formation, review and editing of the paper, mentorship. Reham AlJehani: questionnaire formation, proposal, ethical approval, data collection, methods writing, analysis and results writing. Ola H. Abudaowd: questionnaire formation, proposal, ethical approval, data collection, introduction writing, analysis and results writing.

Nada A. Bugshan: ethical approval, data collection, discussion writing, analysis and results writing, submission.

\section{Funding}

The study did not receive any external funding.

\section{Conflict of interests}

The authors declare that there are no conflicts of interests.

Data and materials availability

All data associated with this study are present in the paper.

\section{REFERENCES AND NOTES}

1. Abahussin M, AlAnazi M, Ogbuehi KC, Osuagwu UL. Prevalence, use and sale of contact lenses in Saudi Arabia: survey on university women and non-ophthalmic stores. Cont Lens Anterior Eye 2014; 37(3):185-90.

2. Abbouda A, Restivo L, Bruscolini A, Pirraglia MP, De Marco F, La Cava M, Pivetti Pezzi P. Contact Lens Care among Teenage Students in Italy: A Cross-Sectional Study. Semin Ophthalmol 2016; 31(3):226-32.

3. Albasheer OB, Abdelmola AO, Hanani A, Zogbhy A, Mrair A, Badawi F, Hakami S, Abuhekmah G, Ayoub L, Hakami A. Awareness and practice regarding contact lens wearing and related complications among Jazan University students; Saudi Arabia. Medical Science 2021;25(111):1233-1240
4. Alobaidan OS, Alkhalifah MK, AlSayegh AA, Alhumaid FA, Ashammery AS, Alghamdi K, Mousa A, Khandekar R, AlRashid W. Knowledge and practice regarding contact lens among Saudi urban contact lens users. Saudi J Ophthalmol 2018; 32(2):93-6.

5. American Optmometric Association. Types of contact lenses. https://www.aoa.org/healthy-eyes/vision-and-visioncorrection/types-of-contact-lenses?sso=y. Accessed: 10July 2021.

6. Bamahfouz AY, Nafady-Hego H, Jouhargy S, Abdul Qadir M, Qutub WNJ, Bahubaishi K, M.,, Al-ghamdi AA. Awareness of Contact Lens Care among College Students in Saudi Arabia. Int J Sci Study 2016; 4(1):90-6. 
7. Becmeur PH, Abry F, Bourcier T, Meyer N, Sauer A. [Risk factors for contact lens-related microbial keratitis: A multicenter case-control study]. J Fr Ophtalmol 2017; 40(3):224-31.

8. Berenson AB, Chang M, Hirth JM, Merkley KH. Use and misuse of cosmetic contact lenses among US adolescents in Southeast Texas. Adolesc Health Med Ther 2019; 10:1-6.

9. Boyd K. How to take care of contact lenses: American Academy of Ophthalmology; 2021]. https:/www.aao.org/ eye-health/glasses-contacts/contact-lens-care. Accessed: 10 July 2021.

10. Bui TH, Cavanagh HD, Robertson DM. Patient compliance during contact lens wear: perceptions, awareness, and behavior. Eye Contact Lens 2010; 36(6):334-9.

11. Contact Lens Health Week - August 19-23, 2019. MMWR Morb Mortal Wkly Rep 2019; 68(32):693.

12. Cope JR, Collier SA, Srinivasan K, Abliz E, Myers A, Millin CJ, Miller A, Tarver ME. Contact Lens-Related Corneal Infections - United States, 2005-2015. MMWR Morb Mortal Wkly Rep 2016; 65(32):817-20.

13. Dakhil TAB, Almutiri RH, Althubaity AM, Alharthi AK, Altowairqi MA, Alshubayni AM, Alanazi AA. Prevalence of eye infection among contact lenses users compared to nonusers, Saudi Population, 2019. Medical Science 2020;24(103): 1067-1074

14. Goodlaw E. Risk of infection from sleeping with contact lenses on: causes of risk. Optom Vis Sci 1996; 73(3):156-8.

15. Gyawali R, Nestha Mohamed F, Bist J, Kandel H, Marasini $S$, Khadka J. Compliance and hygiene behaviour among soft contact lens wearers in the Maldives. Clin Exp Optom 2014; 97(1):43-7.

16. Hinton P, Mcurray I, Brownlow C. SPSS Explained. 2nd ed. London: Routledge; 2014.

17. Ibrahim NK, Seraj H, Khan R, Baabdullah M, Reda L. Prevalence, habits and outcomes of using contact lenses among medical students. Pak J Med Sci 2018; 34(6):1429-34.

18. Khoza N, Moodley T, Sokhulu S, Sotyana NO, Suliman A, Hansraj R, van Staden D. Knowledge, attitudes and practices of contact lens use in a South African adolescent population. Afr Health Sci 2020; 20(2):768-74.

19. Kilvington S, Powell CH, Lam A, Lonnen J. Antimicrobial efficacy of multi-purpose contact lens disinfectant solutions following evaporation. Cont Lens Anterior Eye 2011; 34(4):183-7.

20. Lee SY, Kim YH, Johnson D, Mondino BJ, Weissman BA. Contact lens complications in an urgent-care population: the University of California, Los Angeles, contact lens study. Eye Contact Lens 2012; 38(1):49-52.

21. Lievens CW, Cilimberg KC, Moore A. Contact lens care tips for patients: an optometrist's perspective. Clin Optom (Auckl) 2017; 9:113-21.
22. Nichols KK, Redfern RL, Jacob JT, Nelson JD, Fonn D, Forstot SL, Huang JF, Holden BA, Nichols JJ. The TFOS International Workshop on Contact Lens Discomfort: report of the definition and classification subcommittee. Invest Ophthalmol Vis Sci 2013; 54(11):TFOS14-9.

23. Stapleton F, Keay L, Jalbert I, Cole N. The epidemiology of contact lens related infiltrates. Optom Vis Sci 2007; 84(4):257-72.

24. Suvajac G. [Soft-contact-lenses-induced complications]. Vojnosanit Pregl 2008; 65(1):15-20.

25. Tajunisah I, Ophth M, Reddy SC, Phuah SJ. Knowledge and practice of contact lens wear and care among medical students of University of Malaya. Med J Malaysia 2008; 63(3):207-10.

26. U.S. Food and Drug Administration. "Colored" and decorative contact lenses: a prescription is a must 2016. https://www.fda.gov/ForConsumers/ConsumerUpdates/uc m275069.htm. Accessed: 4 June 2018.

27. Unnikrishnan B, Hussain S. Pattern of use of contact lens among college students: a cross-sectional study in coastal Karnataka. Indian J Ophthalmol 2009; 57(6):467-9.

28. Vijayakumar R, Al-Aboody MS, Alturaiki W, Alsagaby SA, Sandle T. A study of airborne fungal allergens in sandstorm dust in Al-Zulfi, central region of Saudi Arabia. J Environ Occup Sci 2017; 6(1):27-33.

29. Wagner H, Richdale K, Mitchell GL, Lam DY, Jansen ME, Kinoshita BT, Sorbara L, Chalmers RL. Age, behavior, environment, and health factors in the soft contact lens risk survey. Optom Vis Sci 2014; 91(3):252-61.

30. Wu YT, Zhu H, Harmis NY, Iskandar SY, Willcox M, Stapleton F. Profile and frequency of microbial contamination of contact lens cases. Optom Vis Sci 2010; 87(3):E152-8.

31. Zhu Q, Yang B, Deng N, Li Y, Wang T, Qi H, Liu L. The use of contact lenses among university students in Chengdu: Knowledge and practice of contact lens wearers. Cont Lens Anterior Eye 2018; 41(2):229-33. 